\title{
Peppermint (Mentha piperita Huds.) and basil (Ocimum basilicum L.) etheric-oil by-products as roughages for sheep feeding
}

\author{
D Pavlov 1, A llchev 1, D Djouvinov 1, RE Ørskov 2 \\ University of Zootechnics and Veterinary Medicine, Stara Zagora 6000, Bulgaria ; \\ 2Rowett Research Institute, Aberdeen AB2 9SB, UK
}

\begin{abstract}
Stems, leaves and flowers remain after extraction of etheric oils from peppermint and basil. The data about their chemical composition and utilization by ruminants are scarce.
\end{abstract}

The study aimed to determine the nutritive value of whole plants of peppermint and basil after distillation and their influence on some ruminal parameters of sheep.

Digestibility of peppermint and basil was determined after different in vivo trials with wethers applying $3 \times 3$ Latin square design. Three diets were tested : $900 \mathrm{~g}$ dry matter (DM) meadow hay $(\mathrm{H}), 450 \mathrm{~g}$ DM meadow hay plus $450 \mathrm{~g}$ DM peppermint $(P)$ and $450 \mathrm{~g} \mathrm{DM}$ meadow hay plus $450 \mathrm{~g}$ DM basil $(B)$.

The chemical composition of feeds, refusals and faeces was determined following Weende method. Feed units (FU) were calculated from digestibility measurements and feed units for growth (FUG) - according to the new Bulgarian feed evaluation system (Todorov, 1992, Agric Acad, Sofia, Bg, 186). In vitro gas production was measured as described by Menke and Steingass (1988, Anim Res Develop, 28, 7-53). Rumen fluid was analysed for total and individual volatile fatty acids (VFA) using steam distillation and gas chromatography, respectively. Protozoa were counted using a Fux-Rosental counting chamber.

Item

OMD

$\mathrm{FU}(/ \mathrm{kg} \mathrm{DM})$

FUG (/kg DM)

Gas produced ( $\mathrm{ml} / 200 \mathrm{mg} \mathrm{DM})$

$$
7 \mathrm{~h}
$$

$12 \mathrm{~h}$

$24 \mathrm{~h}$

$48 \mathrm{~h}$
Organic matter digestibility (OMD) of basil was the lowest among the tested roughages, while peppermint showed only slight decrease, compared to meadow hay (basal diet). FU and FUG decreased in the order of: hay $>$ peppermint $>$ basil. The data about net energy content of tested feeds were supported by the results of in vitro gas production. The volume of gas produced by basil was similar to that of barley straw, reported by Bluemmel and Ørskov (1993, Anim Feed Sci Technol, 40, 109-119). No differences between the diets were found in $\mathrm{pH}$ and VFA concentration of rumen liquor, which were in the range of 6.57 6.99 and $4.50-5.10 \mathrm{mmol} / \mathrm{dl}$, respectively. Feeding diet $\mathrm{B}$ led to the highest proportion of acetic acid $(75 \%)$ in the rumen liquor which corresponded to the highest crude fiber content of basil. The lowest total protozoa number was counted in the rumen liquor of sheep fed

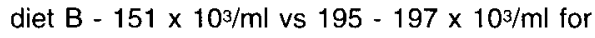
diets $H$ and $P$.

In conclusion, the nutritive value of peppermint by-product after etheric-oil distillation was slightly lower compared to the meadow hay. Basil by-product had nutritive value close to barley straw. The tested by-products, particularly from peppermint, could be used as roughage compound in sheep feeding.

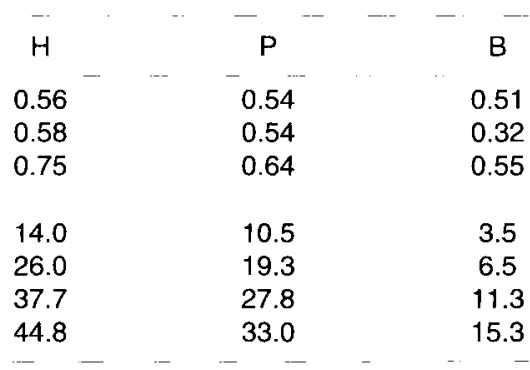

